\title{
Research Paper \\ Predicting the Prevalence of COVID-19 and its Mortality Rate in Iran Using Lyapunov Exponent
}

\author{
${ }^{*}$ Fatemeh Mohammadi ${ }^{1}$ (1), Saeedeh Kouzehgari² ${ }^{2}$
}

1. Department of Biomedical Engineering, Faculty of Medical Science and Technologies, Science and Research Branch, Azad University, Tehran, Iran. 2. Department of International Relations, Faculty of Humanities, Tarbiat Modares University, Tehran, Iran.

\begin{tabular}{c|l}
$\begin{array}{c}\text { Use your device toscan } \\
\text { and read the atrice online }\end{array}$ \\
Citation Mohammadi F, Kouzehgari S. Predicting the Prevalence of COVID-19 and its Mortality Rate in Iran Using Lyapunov Exponent. \\
The Journal of Qazvin University of Medical Sciences. 2020; 24(2):108-123. https://doi.org/10.32598/JQUMS.24.2.2415.1 \\
doi https://doi.org/10.32598/JQUMS.24.2.2415.1
\end{tabular}

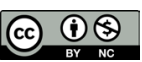

Received: 9 Jun 2020

Accepted: 25 Jun 2020

Available Online: 30 Jun 2020

Keywords:

COVID-19, Preva-

lence, Mortality, Iran, Chaos theory, Lyapunov exponent

\section{A B STR ACT}

Background COVID-19 was first reported in late December 2019 in Wuhan, China, and spread rapidly throughout the world including Iran.

Objective The purpose of this paper is to predict the prevalence of coronavirus and the number of confirmed cases and deaths in Iran based on the theory of chaos and measuring the Lyapunov exponent. Methods In this analytical study, the number of confirmed cases, recovered patients, total tests, and deaths between February 20 and May 30, 2020 were collected daily from the website of the Iranian Ministry of Health and Medical Education. The prevalence rate and the time to reach saturation in a short period were estimated using a formula using Lyapunov exponent and the initial and final number of confirmed cases in Matlab software.

Findings Simulation of all confirmed cases between 20 February 2020 to 4 May 2020 show the number of people infected with the coronavirus would be close to saturation, but in end of May 2020 the number of people with the disease re-entered the second phase of increase. The slope of the simulation curve decreases in the second phase and the virus spreads in May at a slower rate than in the first phase (April). The simulation diagram of the total confirmed patients to the total number of tests performed also shows the entry into the second phase of increasing in May.

Conclusion Simulation results of all confirmed cases and total deaths in Iran, using chaos theory and the Lyapunov-based model, can properly represent the real data and can predict the trend of spread and time to approach saturation in a short time. Sensitivity to the initial condition in the equation by changing the quarantine restrictions and the observance of health protocols causes a change in the rate of total number of confirmed patients enters the third or fourth increasing phase. Also, based on the calculated deaths, it is predicted that the total number of deaths at the end of May will reach less than $5 \%$ of the total number of people who have recovered and died.

\section{Extended Abstract}

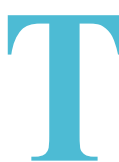

\section{Introduction}

he prevalence of infectious and epidemic diseases has always been associated with many adverse effects and changes. Mathematical modeling of the spatial and temporal spread of infectious diseases and their epidemic simulation has been the subject of a number of studies [1-4]. Most models are based on solving the governing differential equations by simplifying the problem $[9$, 10]. Others try to study this process using the statistics and

* Corresponding Author:

Fatemeh Mohammadi

Address: Department of Biomedical Engineering, Faculty of Medical Science and Technologies, Science and Research Branch, Azad University, Tehran, Iran Tel: +98 (917) 3873274

E-Mail: fateme.mohammadi86@gmail.com 
probability [8], but unfortunately these models are usually not able to explain the details and study them properly due to many simplifications.

The behavior of epidemics, like all living and biological systems, is chaotic. Chaos reflects the behavior of natural and living systems over time. This behavior occurs in natural and biological systems due to the interactions and the emergent properties and sensitivity to initial conditions; therefore, the spread of the virus reflects a chaotic behavior. Given the recent and serious crisis of Covid-19 virus in Iran and many countries around the world, we need a scientific analysis to be able to estimate the necessary predictions of the spread of this disease. Using chaos theory and calculating Lyapunov exponent, this paper aimed to predict the number of coronavirus cases in Iran in a short period and estimate the time of reaching saturation. It also analyzes the recovered and death rates.

\section{Materials and Methods}

In this analytical study, all statistics including the total number of coronavirus confirmed cases, recovered cases, tests, and deaths were collected from the website of the Iranian Ministry of Health and Medical Education from February 20 to May 30, 2020, and then entered into the MATLAB software. The theory of chaos (derived from the principle of chaos that governs the behavior of nature) emerged as a mathematical approach in the natural sciences and was used to model dynamic and complex systems in order to establish a kind of adaptation in relation to the environment, like living organisms, and to create effects similar to reality [18]. One of the characteristics of nonlinear dynamic systems is the sensitivity to initial condition. A slight change in the initial conditions of such systems can cause many changes in the next step [19]. Therefore, the behavior of nonlinear dynamic systems cannot be predicted in the long run. It can only be estimated and predicted in a short time. Sensitivity to initial conditions can be measured by Lyapunov exponents [23]. It provides a valuable tool for measuring chaos in the environment or genetics that are important in shaping social diversity, determining the spread of epidemics, or establishing a new mutation [27]. Therefore, Lyapunov exponent was used in this study to estimate the chaotic prevalence of coronavirus. It can estimate the time the coronavirus outbreak needs to reach saturation and the increasing trend of its cases in a short period. Using the Formula 1, which is based on the calculation of Lyapunov exponent from time-series data, the trend of increase in the number of confirmed cases is simulated in specific time intervals:

$$
\text { 1. } N(d)=\frac{d_{0} d_{\infty}}{d_{0}+d_{\infty} e^{-\lambda d}}
$$

Where, $d$ represents days (the number of days in the time interval), $\mathrm{N}(\mathrm{d})$ indicates the total number of infected cases per day, $\mathrm{d} 0$ is the initial number of infected cases, $\mathrm{d} \infty$ is the final number of infected cases, and $\lambda$ represents Lyapunov exponent (growth rate of the curve).

\section{Results}

Simulation of all confirmed cases between 20 February 2020 to 4 May 2020 show the number of people infected with the coronavirus would be close to saturation, but in end of May 2020 the number of people with the disease re-entered the second phase of increase. The slope of the simulation curve decreases in the second phase and the virus spreads in May at a slower rate than in the first phase (April). The simulation diagram of the total confirmed patients to the total number of tests performed also shows the entry into the second phase of increasing in May.

\section{Discussion}

In the present study, simulation of the total number of confirmed cases, deaths and recovered cases in Iran based on chaos theory and Lyapunov exponent was able to properly represent the real data of the disease cases, and could predict the prevalence and spread of the disease and the time to reach saturation in a short period. According to the results, the total number of coronavirus confirmed cases in Iran was expected to be saturated in the second half of April 2020, but with the change of social conditions and reduction of restrictions, the total number of coronavirus cases entered its second increasing phase and was expected to increase in May. The results showed an increase in the rate of recovered cases from the second half of March to the second half of May (from $82 \%$ to $93 \%$ ), and the mortality rate was expected to reach less than $5 \%$ of the total number of deaths and recovered cases by June.

Due to the chaotic spread of the virus, a little change in the initial conditions, (imposing or relaxing restrictions, people's observance of health protocols, genetic mutation of the virus, gathering in public places, finding definitive treatment/vaccine and etc.) causes many changes in disease outbreak. The findings of the present study can be useful for short-term strategic decisions and providing solutions on how to deal with the virus and how it spreads. 


\section{Ethical Considerations}

Compliance with ethical guidelines

There were no ethical considerations to be considered in this research.

Funding

This research did not receive any grant from funding agencies in the public, commercial, or non-profit sectors.

Authors' contributions

Writing, methodology and aata analysis: Both authors; Resources and validation: Fatemeh Mohammadi; Project administration, writing - review \& editing: Saeedeh Kouzehgari.

Conflicts of interest

The authors declared no conflict of interest. 


\title{
يبشبينى شيوع بيمارى كوويد ـ 19 و مركىوميرهاى ناشى از آن در ايران بر اساس نماى ليإيانوف
}

\author{
"فاطمه محمدى' ه، سعيده كوزهرى
}

ا. كرووه مهيندسى يزشكى، دانشكده علوم وفنون يزشكى، واحد علوم و تحقيقات، داتشكاه آزاد، تهران، ايران.

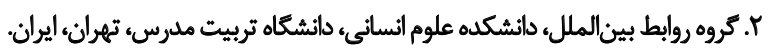

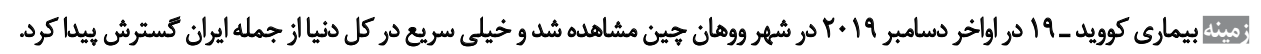

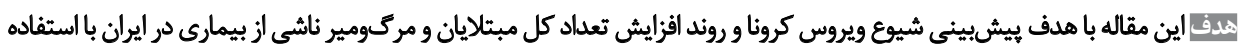

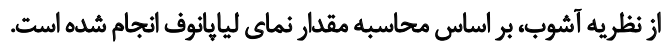

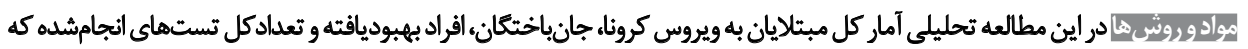

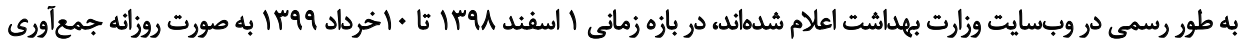

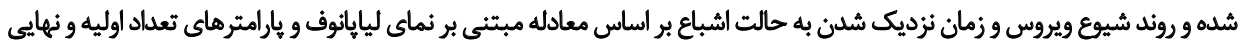

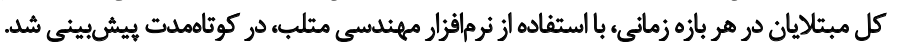

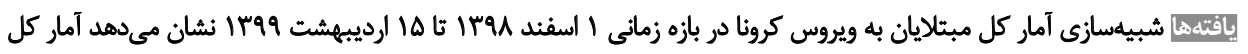

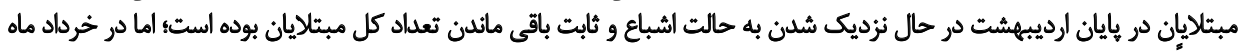

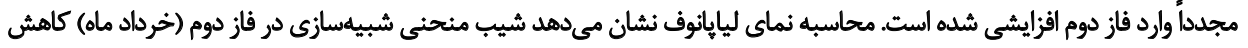

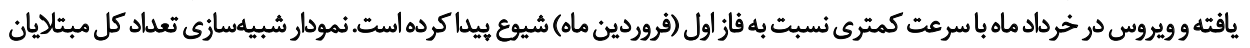

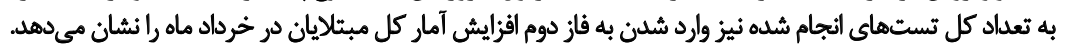

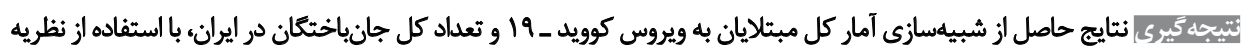

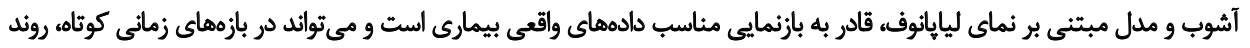

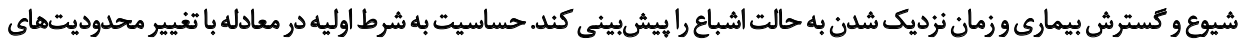

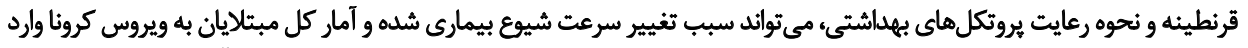

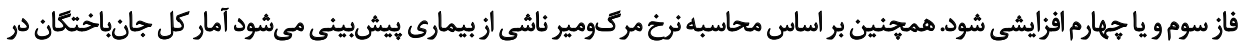

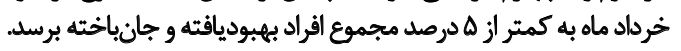

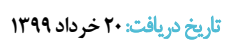

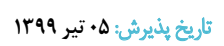

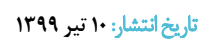

:bogiguls

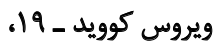

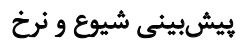

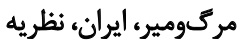
آشوب، نماى لياهيانوف ائن

يك ماه شيوع ويروس در بيش از عها كشور جهان تأييد شد و

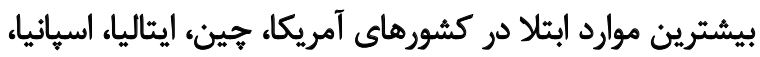

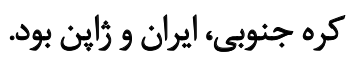

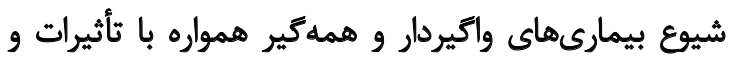

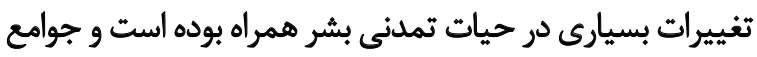

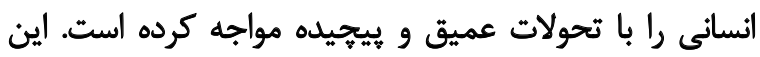

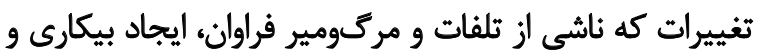

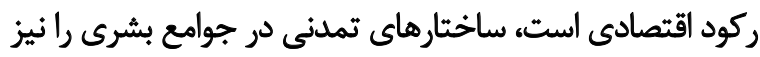

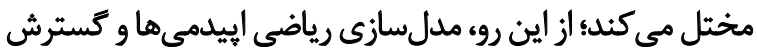

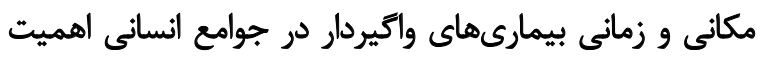

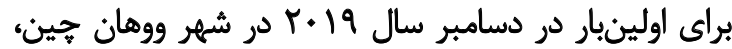

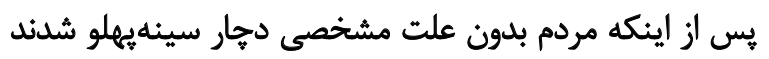

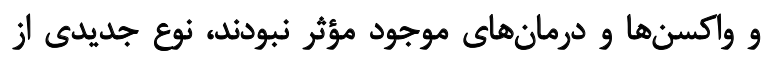

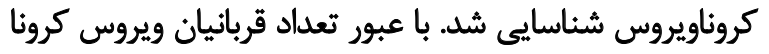

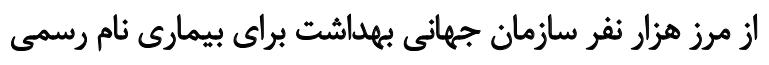

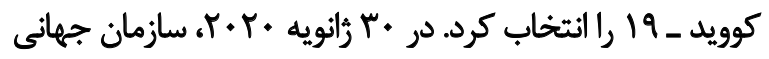

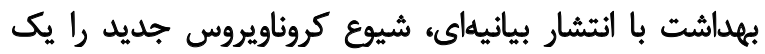

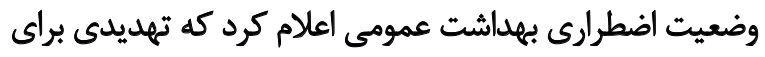

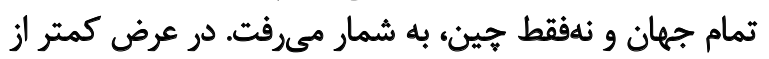




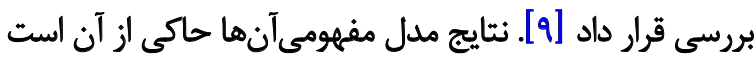

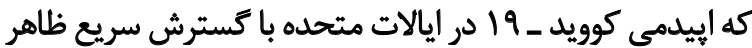

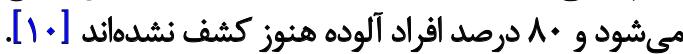

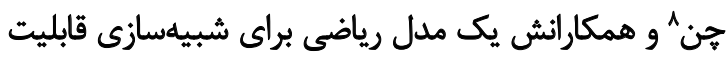

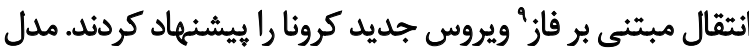

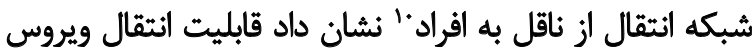

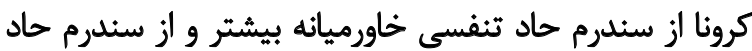

تنفسى در جمهورى كره، كمتر است [ارمان [11].

مرورى بر اين مطالعات و يروهشهاى مشابه نشان مىدهد

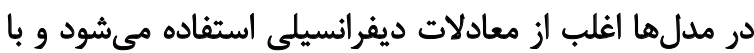

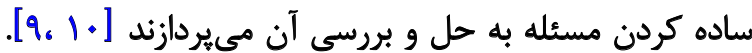

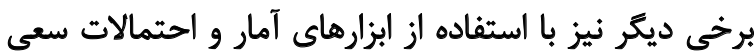

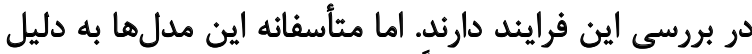

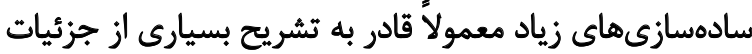
و بررسى صحيح آنها نيستند [A]]. رفتار اييدمىها مانند تمام سيستمهاى زنده و بيولوزيكى،

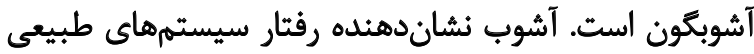
و زنده در طول زمان است. اين رفتار به واسطه وفئ وجود

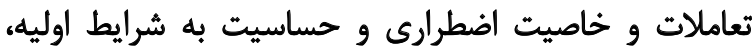

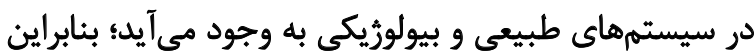

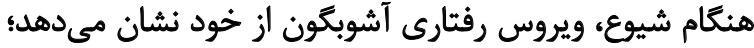

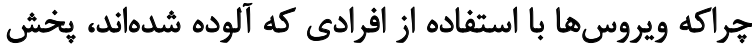

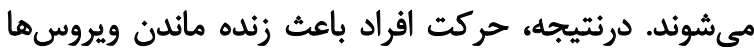

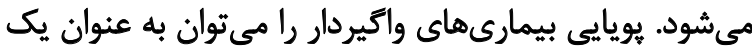

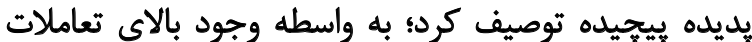

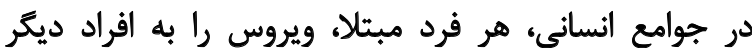

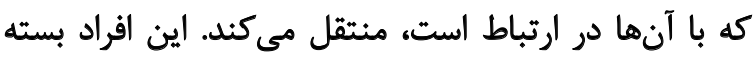

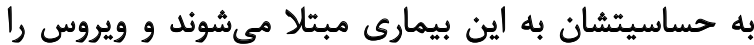

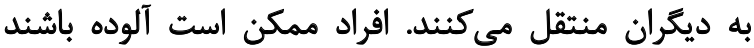

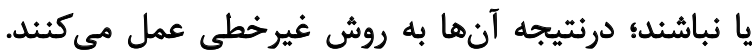

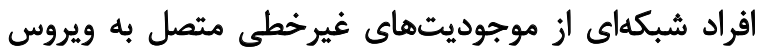

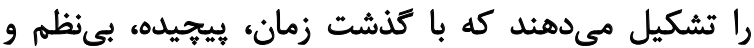

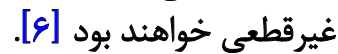

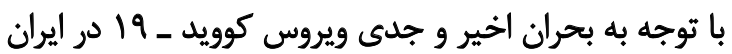

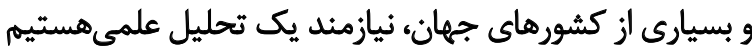

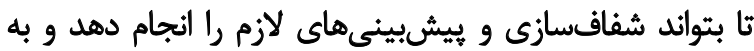

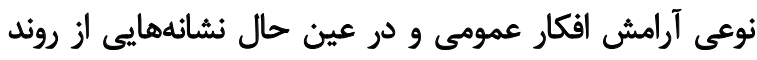

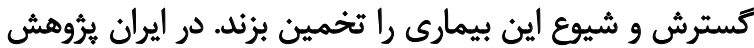

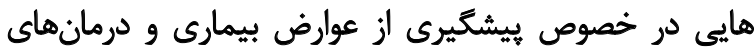
احتمالى، سلامت روانى و اجتماعى و تأثيرات اقتصادى و غيره در دران

\section{Tian-Mu Chen}

9. Simulating the phase-based transmissibility

10. Reservoir-People (RP) transmission network model

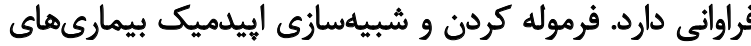

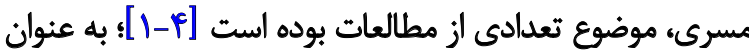

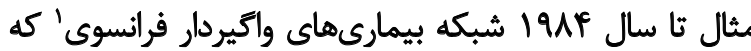

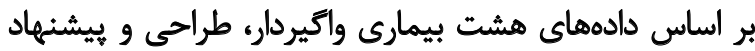

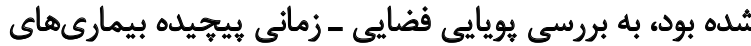

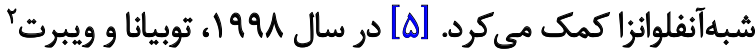

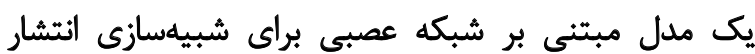

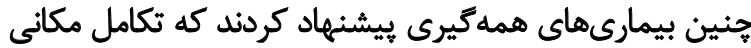

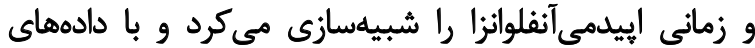

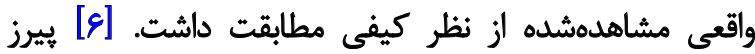

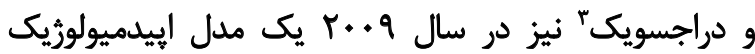

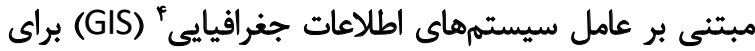
شبيهسازى شيوع بيمارى در محيط شهرى رئر را مورد مطالعه قرار

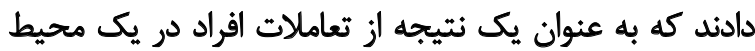

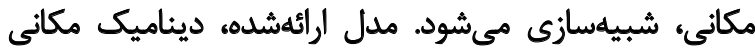

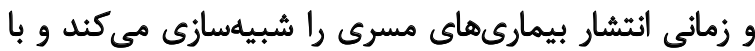

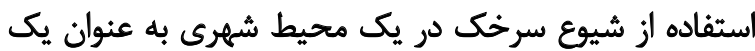

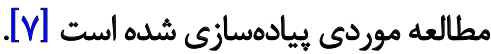

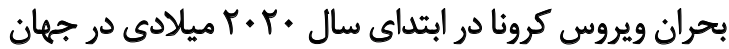

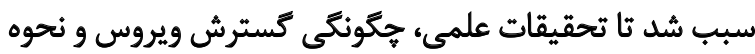

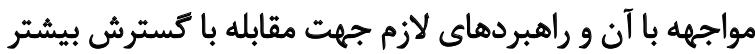

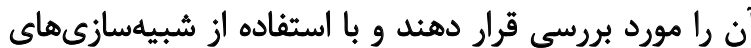

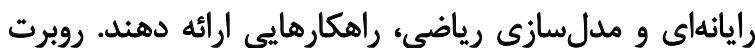

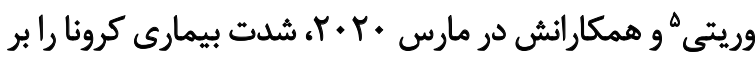

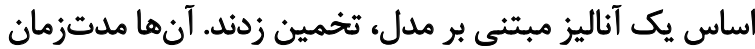

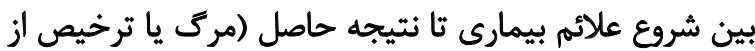

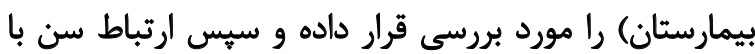

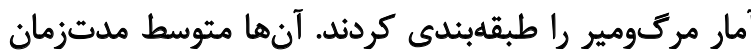

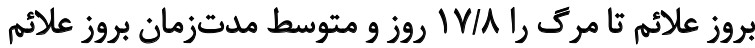

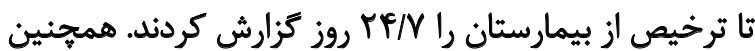

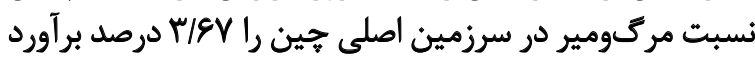

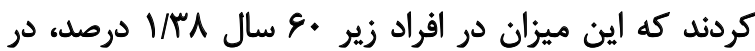

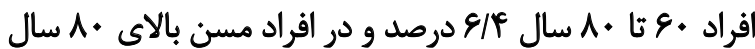

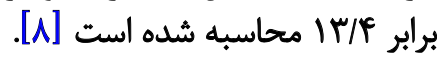

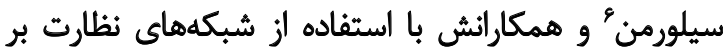

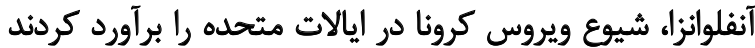

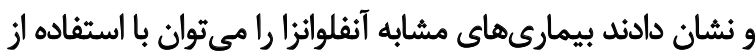

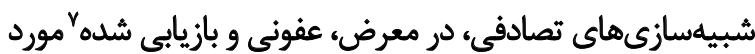

1. French Communicable Disease Network (FCDN)

2. Toubiana \& Vibert

3. Perez, L \& Dragicevic

4. Geographic Information Systems (GIS)

5. Robert Verity

6. Justin D. Silverman

7. Stochastic Susceptible, Exposed, Infectious, and Recovered (SEIR) 


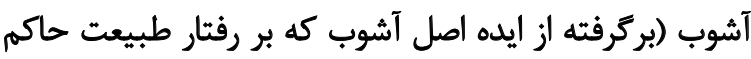

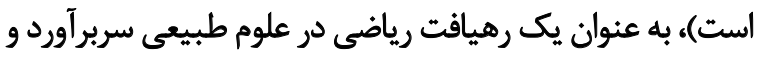

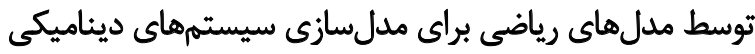

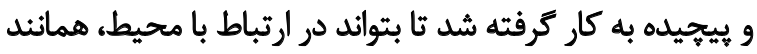

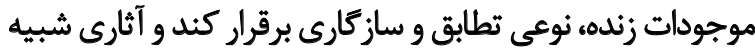

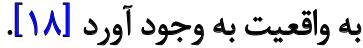

نظريه آشوب برخلاف رهيافتهاى ييشين كهبه تحليل تكسويه

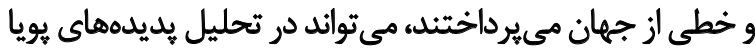

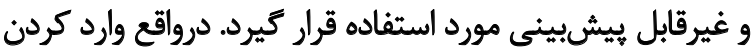
ديناميك غيرخطى ميان عناصر و وعوامل سيستم و بينيجيده كردين

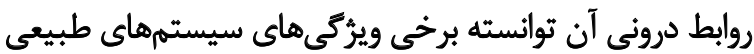

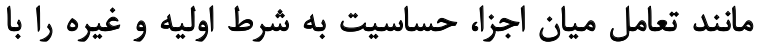

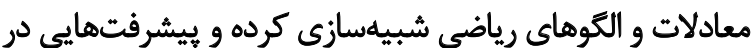

زمينههاي مختلف كسب كند [19].

همانطور كه اشاره شد، يكى از ويرَّىهاى سيستمهاى

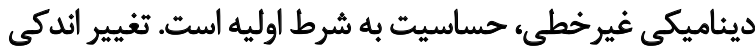

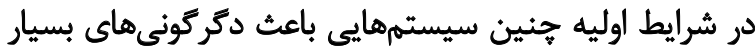

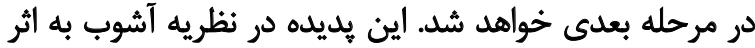

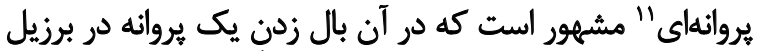

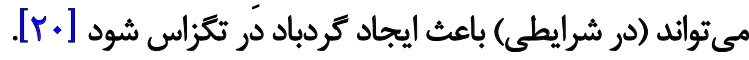
به بيان ديكر حساسيت به شرط اوليه بدين معناست كه هر الهر

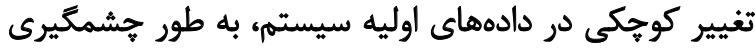

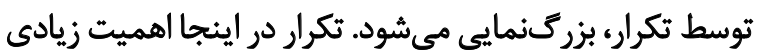

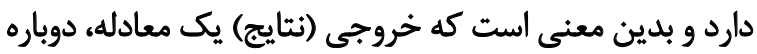

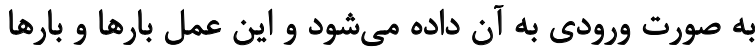

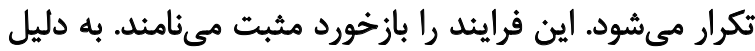

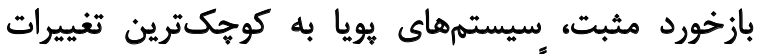

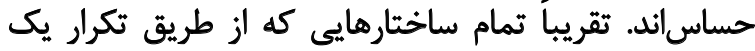

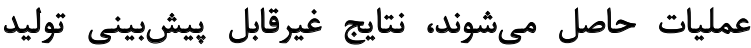

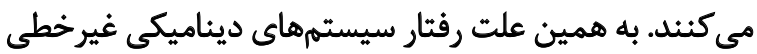

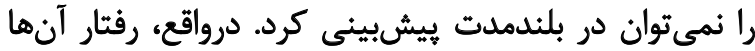

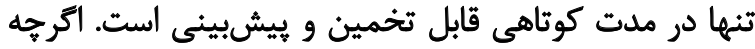

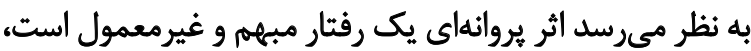

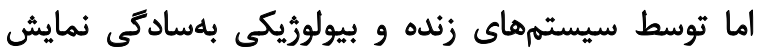

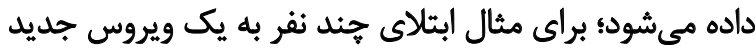

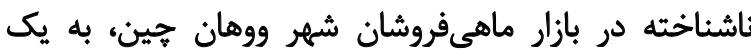

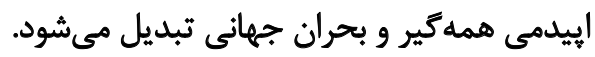

رفتار بهظاهر تصادفى سيستمهاى آشوبكون ناشى از رشدي

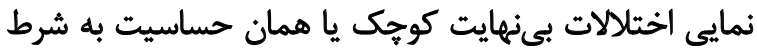

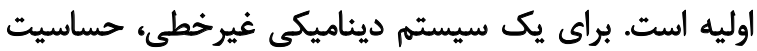

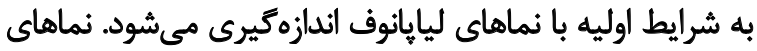

11. Butterfly effect

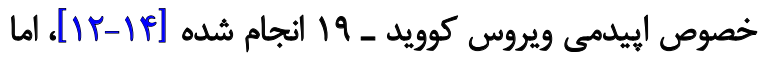

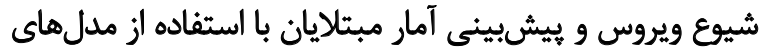
رياضى مورد بررسى قرار نترفته است.

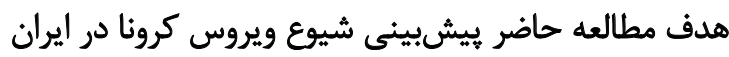

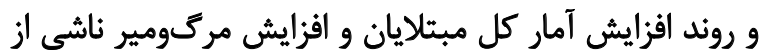

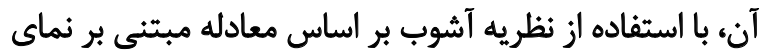
ليايانوف است باست

نماى ليايانوف نمايانتر ميزان حساسيت به شرط اوليه در

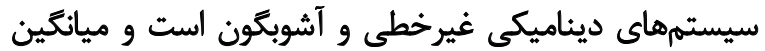

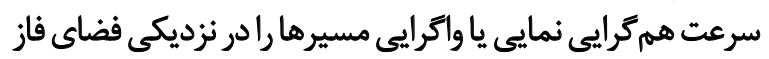

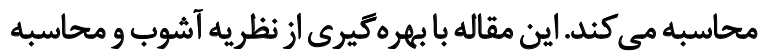

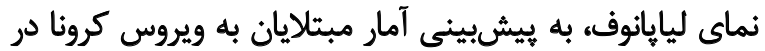

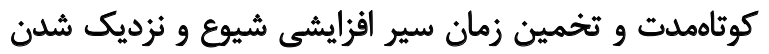

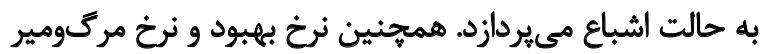
الييدمى را مورد تجزيه و تحليل قرار مى دهدد.

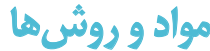

در اين مطالعه تحليلى تمام اعدادو ارقام شامل آمار كل مبتلايان

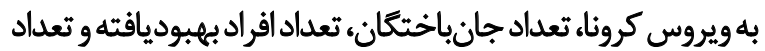

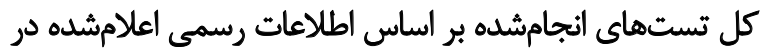

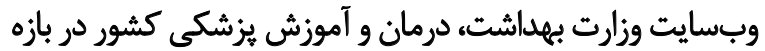

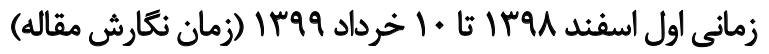
جمعآورى شد و مورد تجزيه و تحليل قرار ترفت التان

$$
\text { نظريه آشوب و نماى ليابائوف }
$$

آشوب در الغت به معنى فقدان سازماندهي، بيىنظمي؛ توده

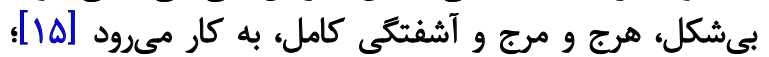

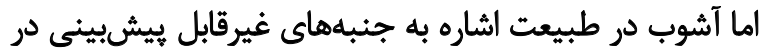

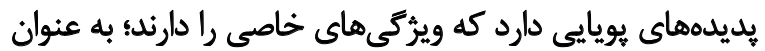

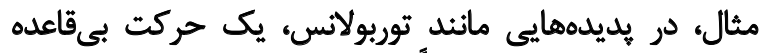

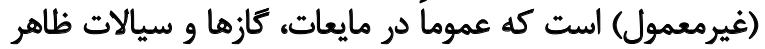

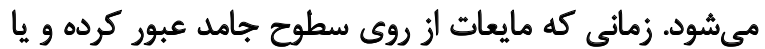

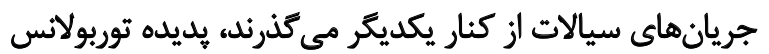

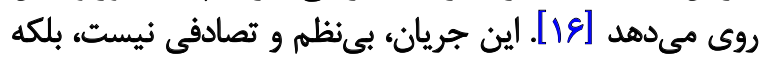

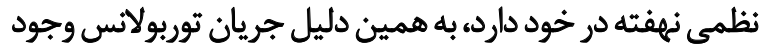

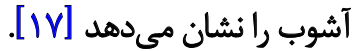

درواقع در طبيعت و سيستمهاى بيولوزيكى، تعاملات و خلق

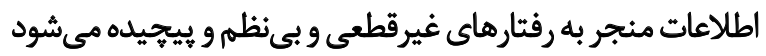

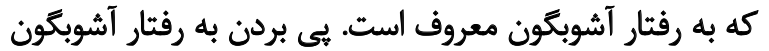

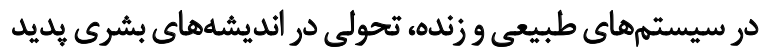

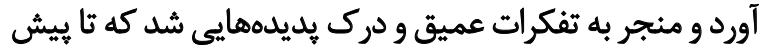

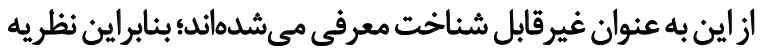




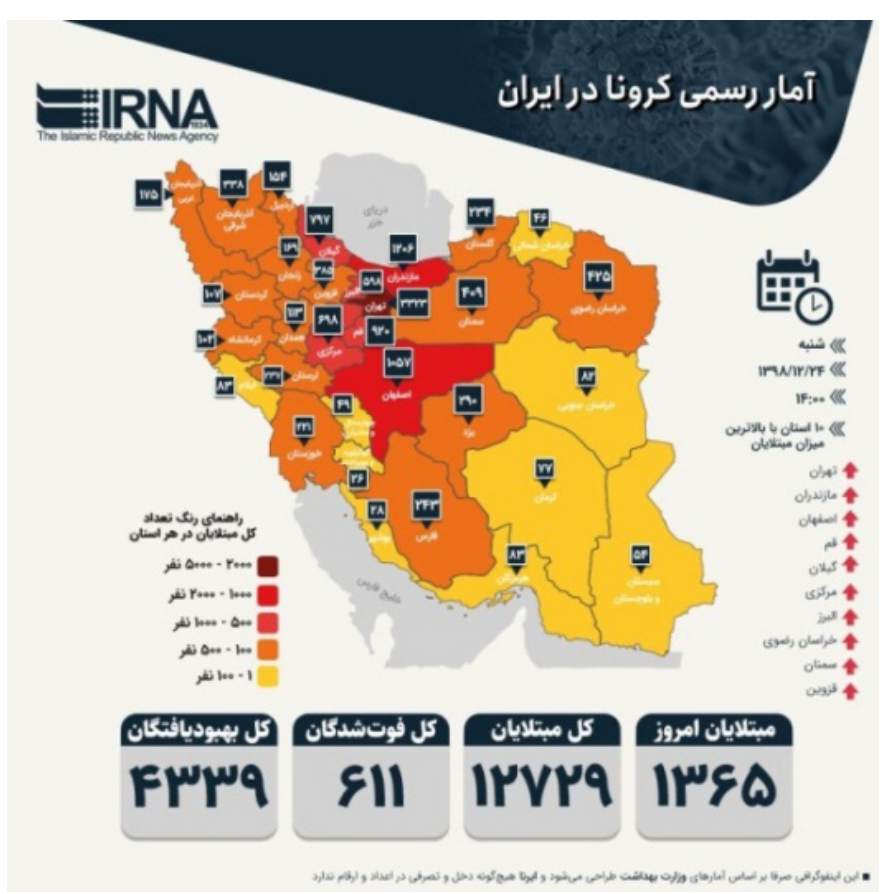

فانستعاهملومينتسكى قزوين

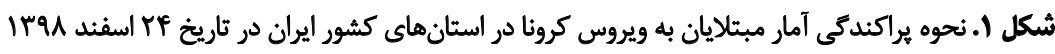

دو نقطه در يك فضا، X

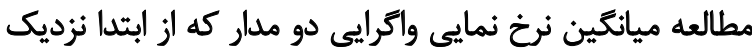

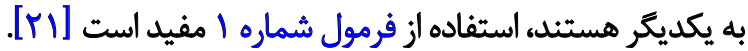

$$
\lambda=\lim _{\substack{t=\infty \\ \Delta x_{0} \rightarrow 0 \mid}} \frac{1}{t} \operatorname{In} \frac{\left|\Delta x\left(x_{0} t\right)\right|}{\Delta x_{0}}
$$

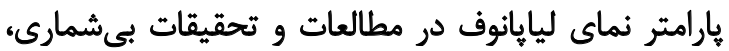

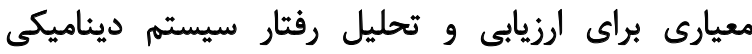

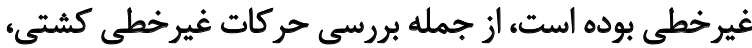

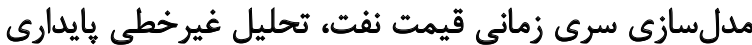

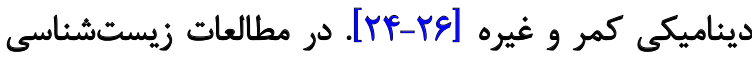

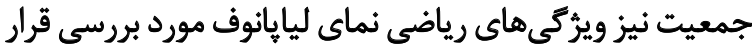

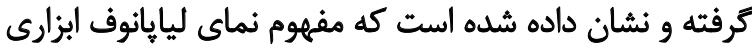

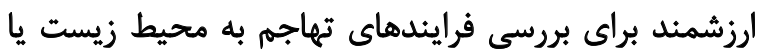

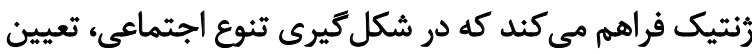

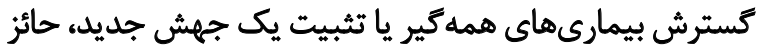

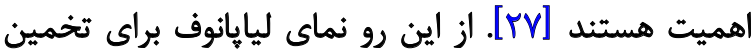

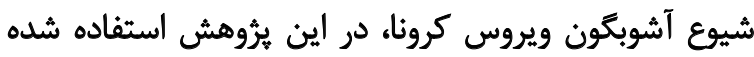

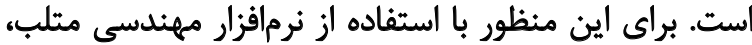

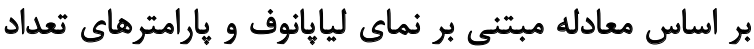

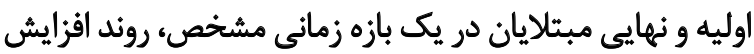

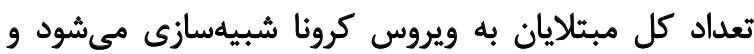

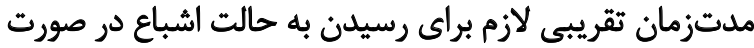

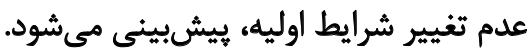

ليايانوف، نايايدارى ذاتى مسيرها (تراركتورىها) رادر يك سيسته نشان ميدهند و ميانكين سرعت همثركايي نماييى يا واكرايي

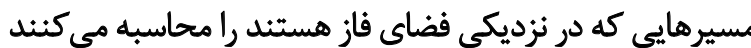

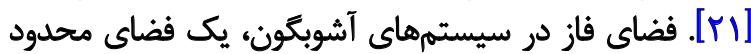

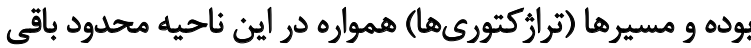

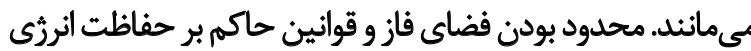

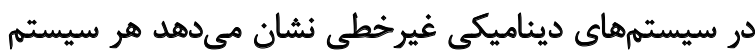

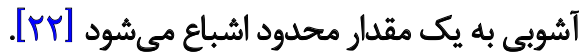

درواقع، نماي ليايانوف، نرخ واكرايى مسيرهاى (تراركتورى)

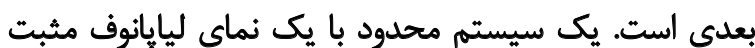

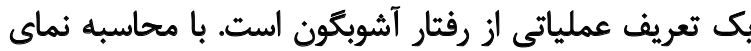

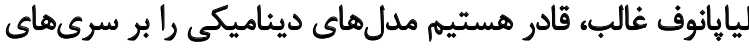

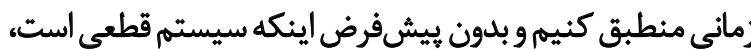

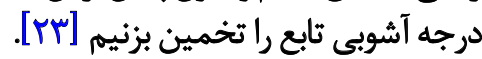

براى نشان دادن ويزّكى هاى سيستمهاى ديناميكى غيرخطى،

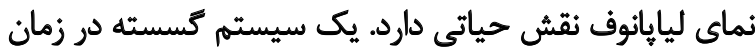

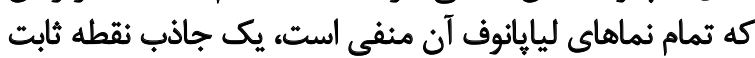

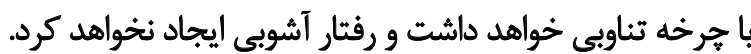

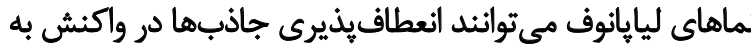

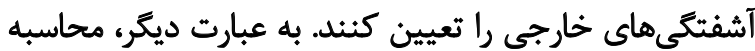

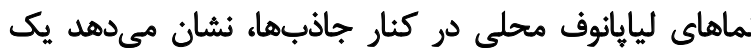

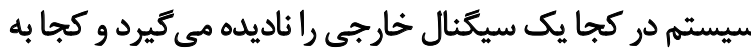

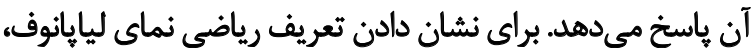




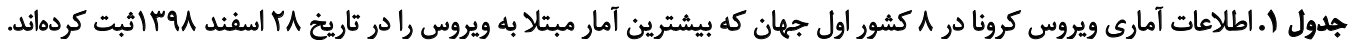

\begin{tabular}{|c|c|c|c|}
\hline كل افراد فوتشده & موارد جديد & كل افراد مبثلا & كشرورها \\
\hline$\pi r V$ & ir & $1 \cdot 194$ & جين \\
\hline$r \Delta \cdot r$ & & M1Q.9 & ايثناليا \\
\hline Mu & & 18159 & ايران \\
\hline ATT & & llare & اسيانيا \\
\hline re & & १स्V & المان \\
\hline Nif & 9 & AFIT & كره جنوبى \\
\hline IVD & & $m+$ & قرائسه \\
\hline 110 & 1.8 & 9010 & آمريكا \\
\hline
\end{tabular}

و سازمانها در جندين استان كاهش يافت. عفونتزدايي

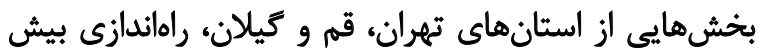

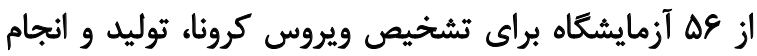

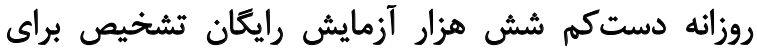

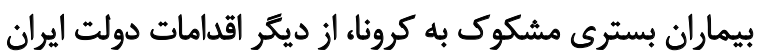

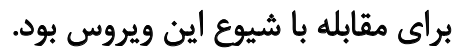

در ب فروردين سال و9 وبا با افزايش تعداد مبتلايان به كرونادر

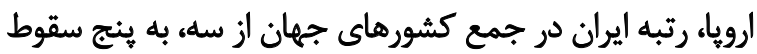

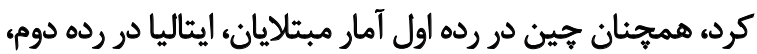

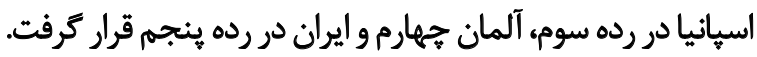

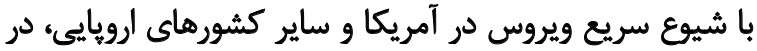

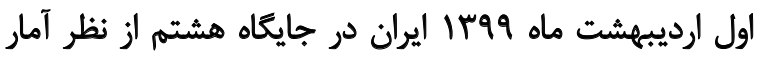
مبتلايان به ويروس كرونا، بعد از آمريكا، اسيانيا، ايتاليا، فرانسه، آنساه آلمان، انكلستان و تركيه قرار گرفت.

آخرين آهارها طبق اعلام وزارت بهداشت، درمان و آموزش

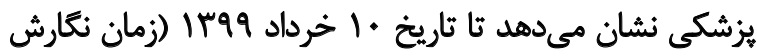

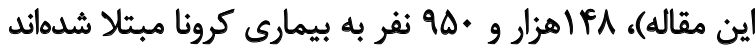

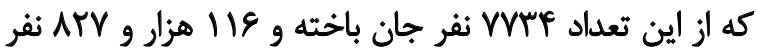

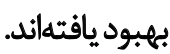

\section{تُخمين شيوع ويروس كرونا در ايران بر اساس نماى يايايانوف}

افزايش سريع و جشمكير آمار مبتلايان به ويروس كرونا در

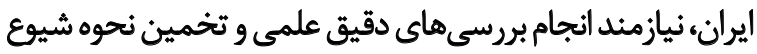

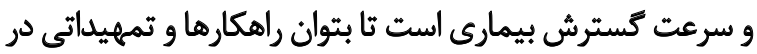

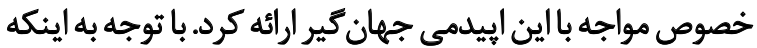

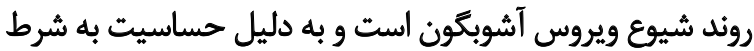

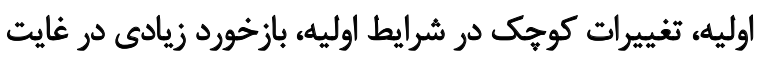

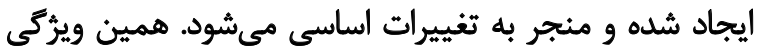

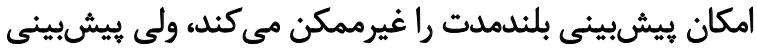

شيوع ويروس كرونا در ايران

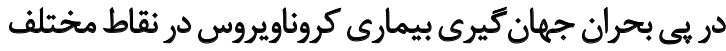

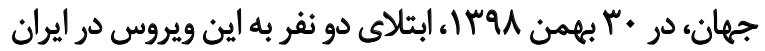

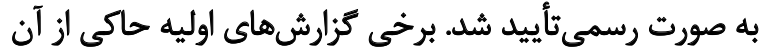

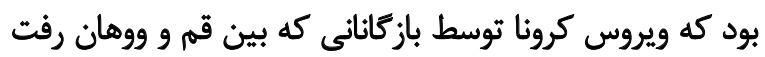

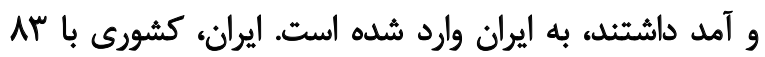

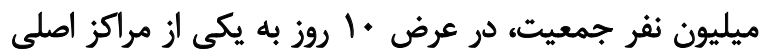

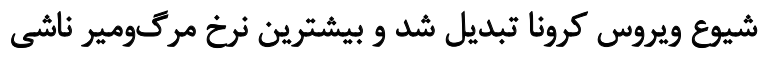

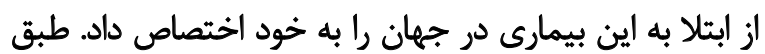

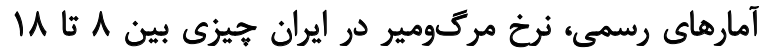

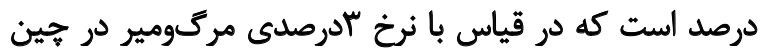

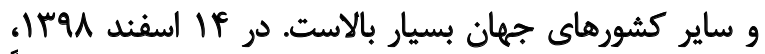

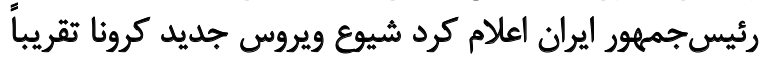

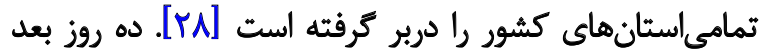

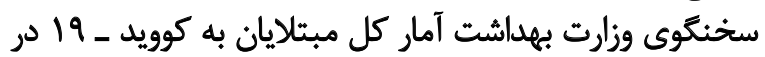

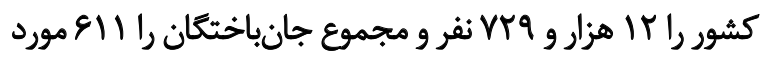

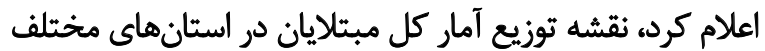
كشور در شكل شماره انشان داده شده است.

سرعت كسترش ويروس كرونا در ايران تا حدى سريع بود كه

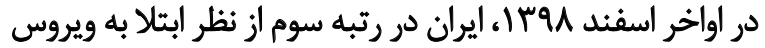

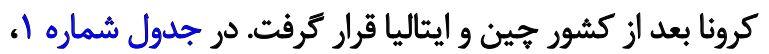

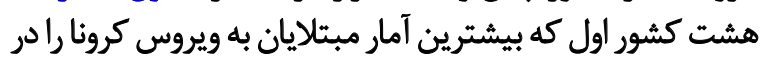

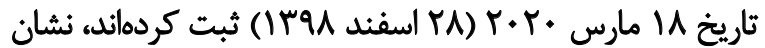

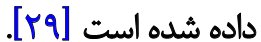
در همان روزهاى ابتدايى همه ميرى ويروس كرونا در ايران،

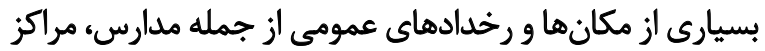

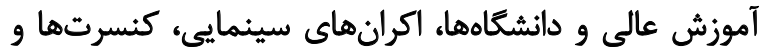

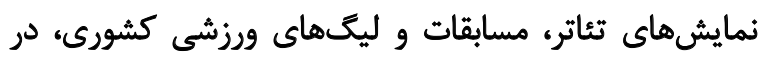

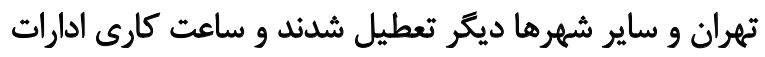




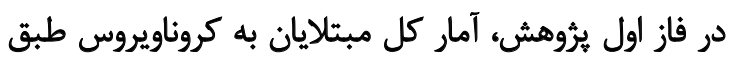

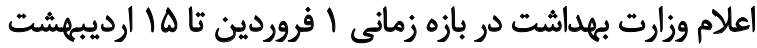

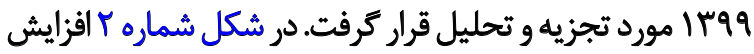

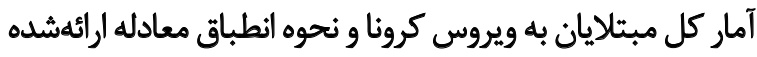

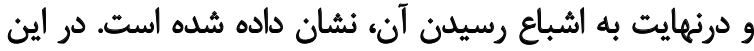

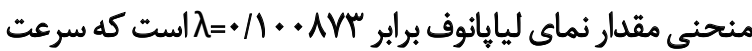
انتشار ويروس را نشان مى دهد.

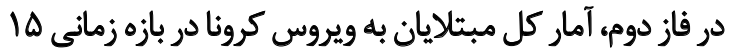

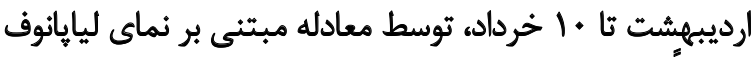

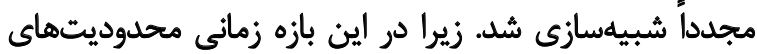

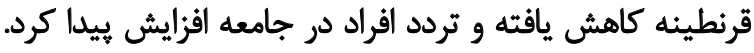

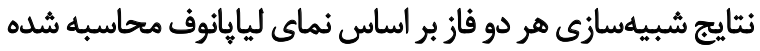

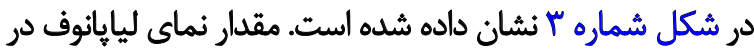

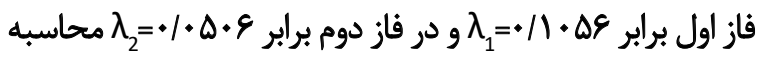

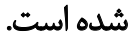

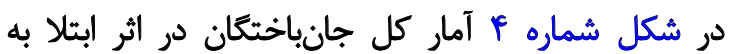

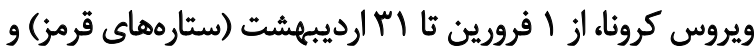

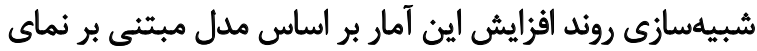
ليايانوف (خط آبى)، نشان داده شده است.

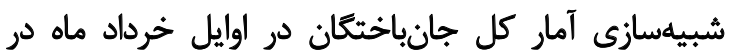

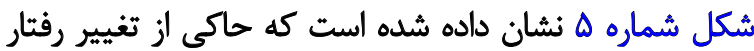

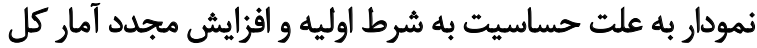

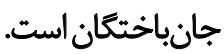
به منظور تجزيه و تحليل دقيقتر دادهها و امكان مقايسه صحيحتر آمار كل مبتلايان به ويروس كرونايل دقيق دادما و طول روزهان مقايه

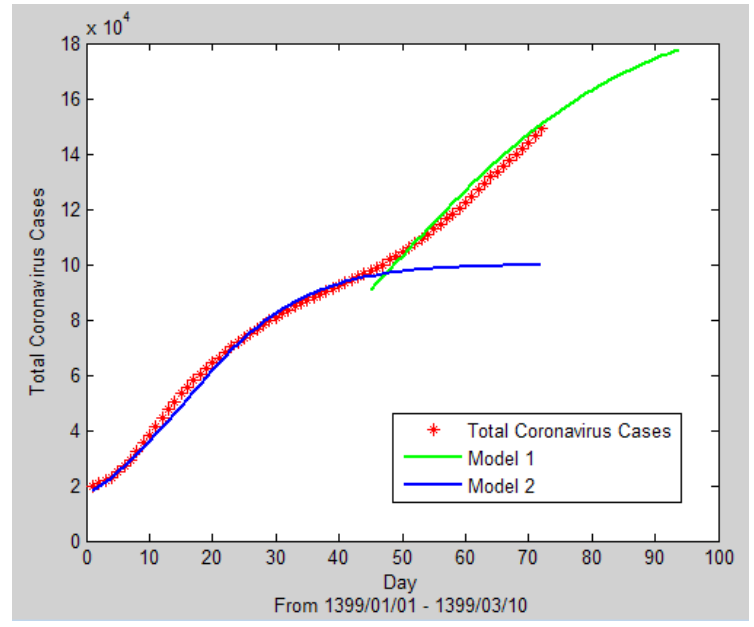

مجلهملمبمى

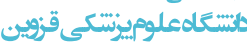

شكل سل نمودار شبيهسازى آمار كل مبتلايان به ويروس كرونا (ستارههاي

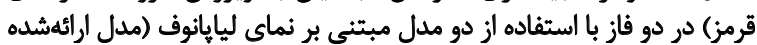

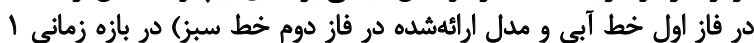

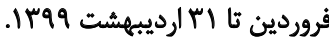

در كوتامدت از طريق برخى مدلهاى رياضى امكانيذير است. مقدار نماى ليايانوف مي تواند زمان رسيدن به اشباع شيوع إنارئ

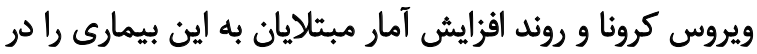

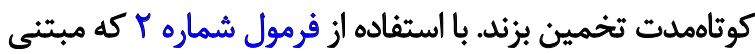

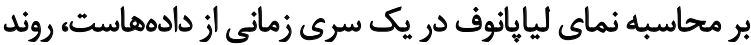

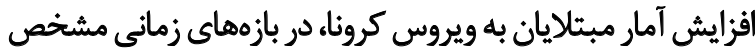

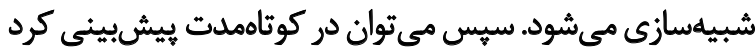

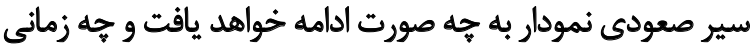

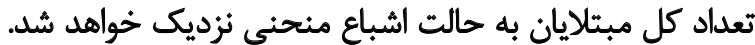

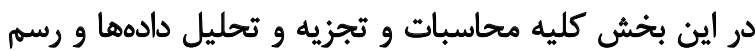

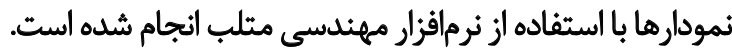

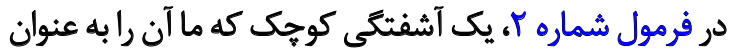

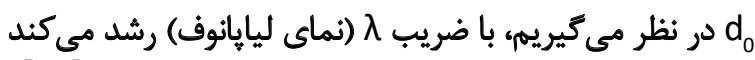

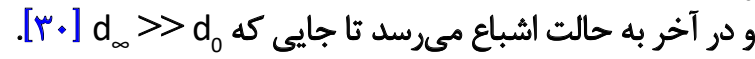

$$
N(d)=\frac{d_{0} d_{\infty}}{d_{0}+d_{\infty} e^{-\lambda d}}
$$

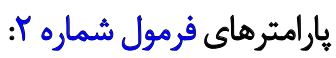

d نمايانكر روزها (به تعداد روزهاى بازه زمانى در نظر كرفته

شدها

تعداد كل مبتلايان به ويروس در هر روز do d تعداد نهايى افراد مبتلا به ويروس גنماى ليايانوف (ضريب رشد منحنى)

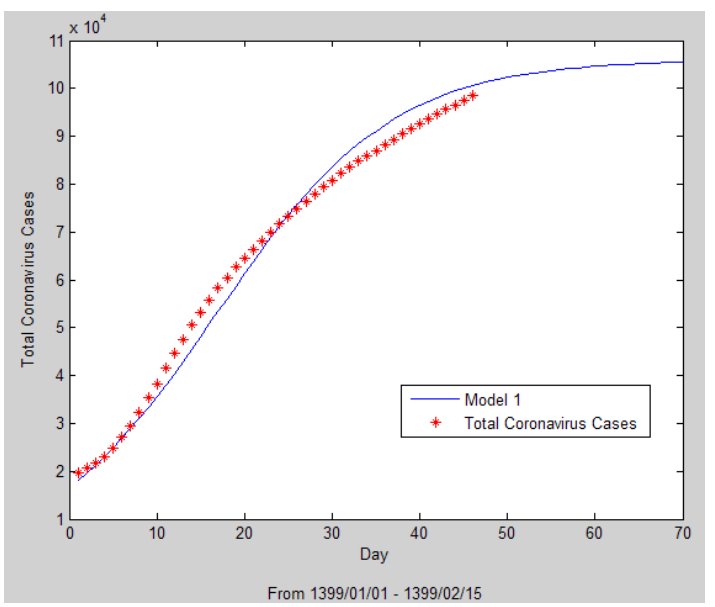

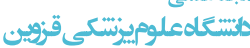

شكل זم تعداد كل مبتلايان به ويروس كرونا در هر روز با ستارههاي قرمز و مدل ارائهده با خط آبى نشان داده شده است. 


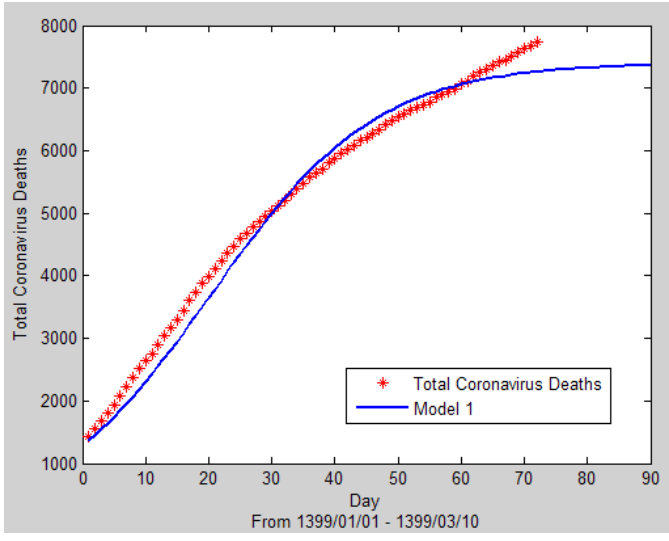

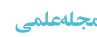

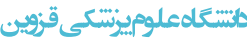

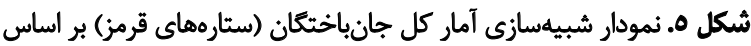

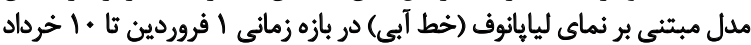

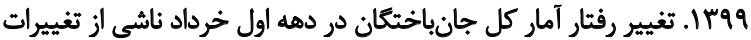
عوامل و حساسيت به شرط اول سيستم

دوباره روند افزايشى بيدا كرد. مدل Y بر مبناى دو نماى ليايانوف r +•|=

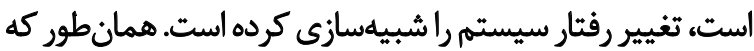

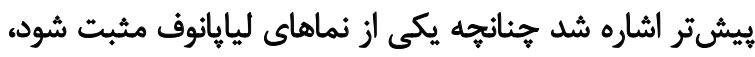

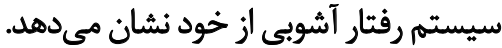

يارامترهاى ديكرى كه مي توان جهت بررسى وضعيت بيمارى

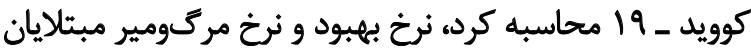

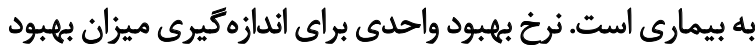

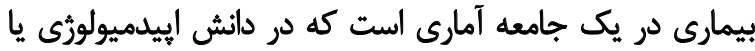
همه كيرشناسى براى آن فرمول مشخصى مورد استفاده قرار مي كئيرد

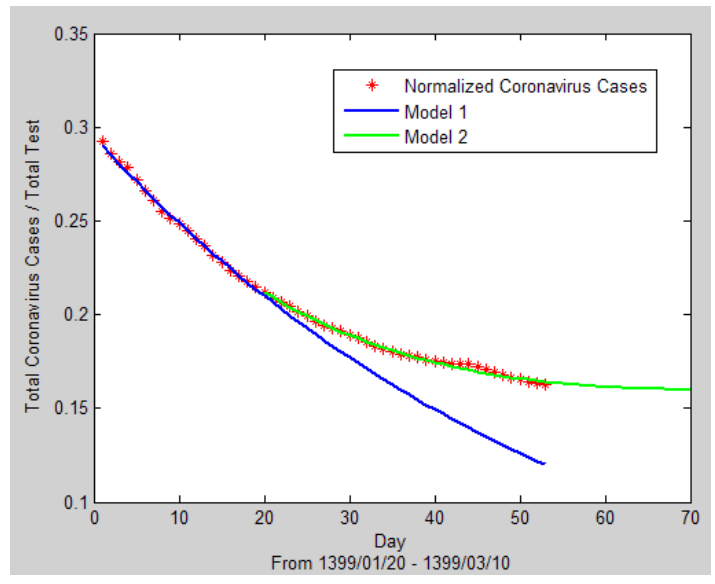

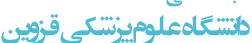

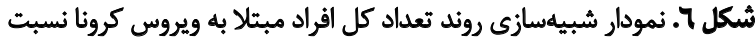

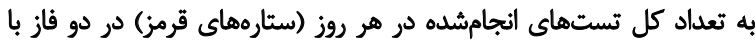

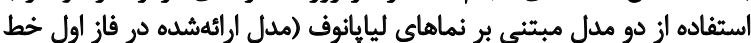

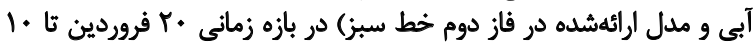

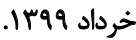

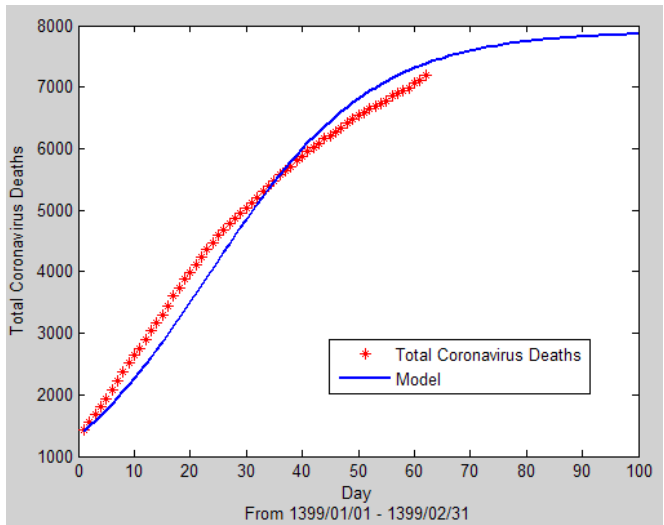

\section{مجلهعلمى مجلهي}

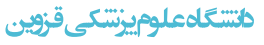

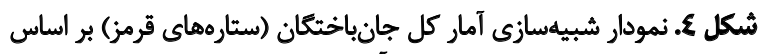

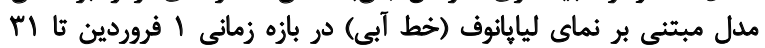

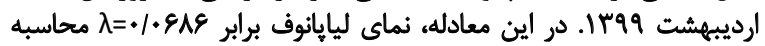
شده است كه نمايانكر سرعت آهسته سير افزايشى تعداد جان بانير باختكان است.

متوالى، بهتر است تعداد كل آزمايشهاى انجامشده در هر روز

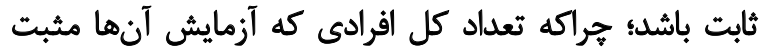

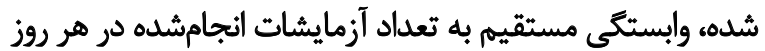

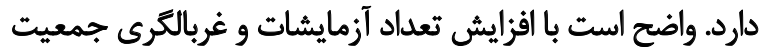

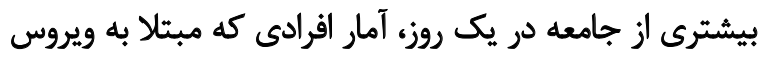

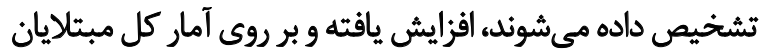
تأثير بسزايى خواهد كذاشت.

طبق آمار اعلامشده از طرف وزارت بهات بهداشت، تعداد كل

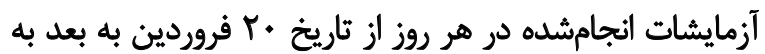

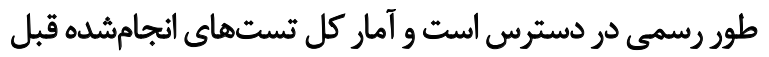

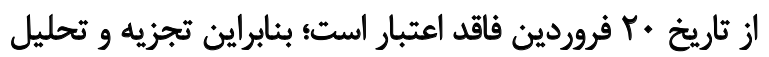

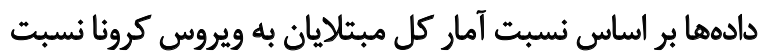

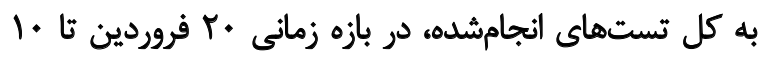
خرداد در شكل شماره 8 نشان داده شده است دماني

همانطور كه در شكل شماره 9 مشاهده مي تشود، نسبت

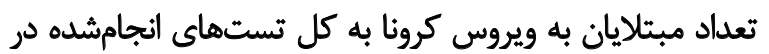

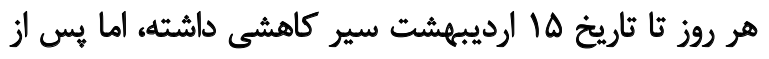

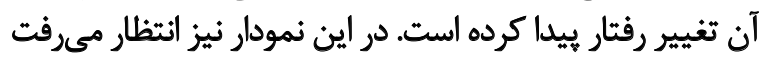

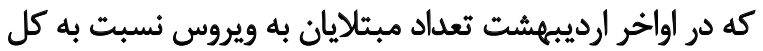

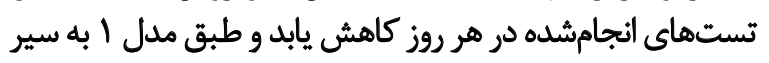

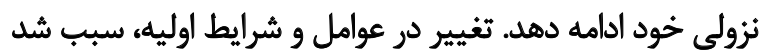
سيستم وارد فاز دوم سير تغيير رفتار خود شود. مدل اول (خط آبى) در اين نمودار داراى يك نماى لمائ ليإيانوف

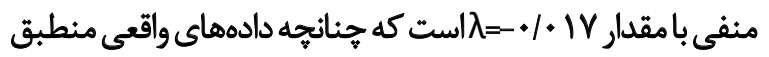

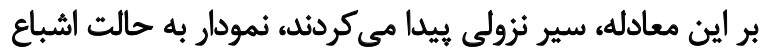

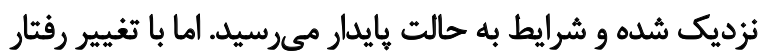

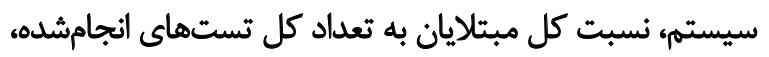


شيب نزولى منحنى در اوايل خرداد نشان مي دهد نرخ مركى برمير افراد مىتواند به كمتر از ه درصد نيز برسد (شكل شماره V). نرخ بهبوديافتكان مبتلا به ويروس كرونا (سمت جي به به رنك

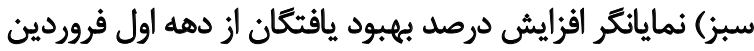

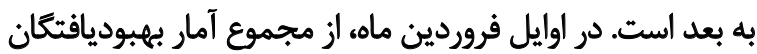

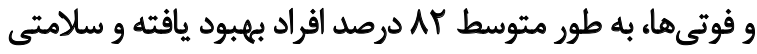

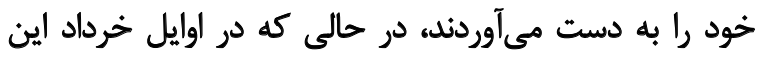
احتمال به بيش از باو درصد افزايش يافته است.

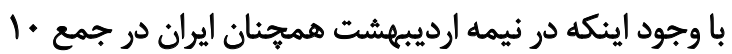

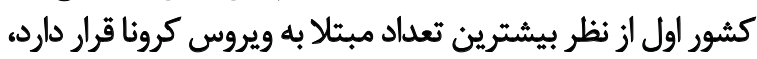

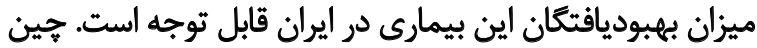

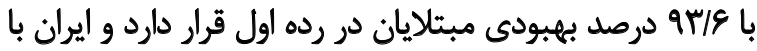

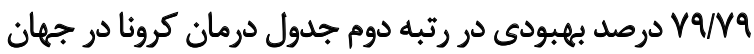

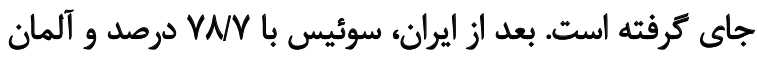

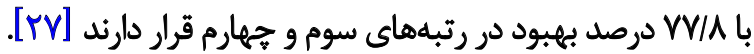

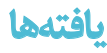

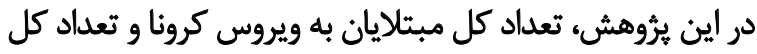

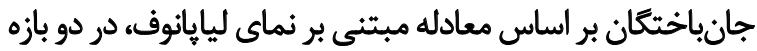

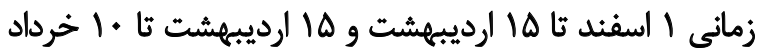

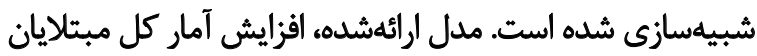

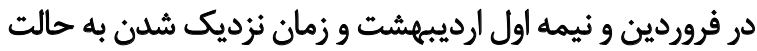

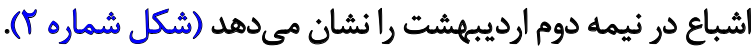

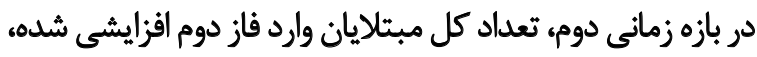

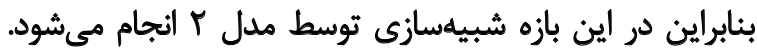

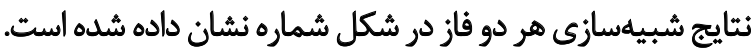
نكته حائز اهميت در شبيهسازى فاز دوم اين است كه مقدار ندار نماى

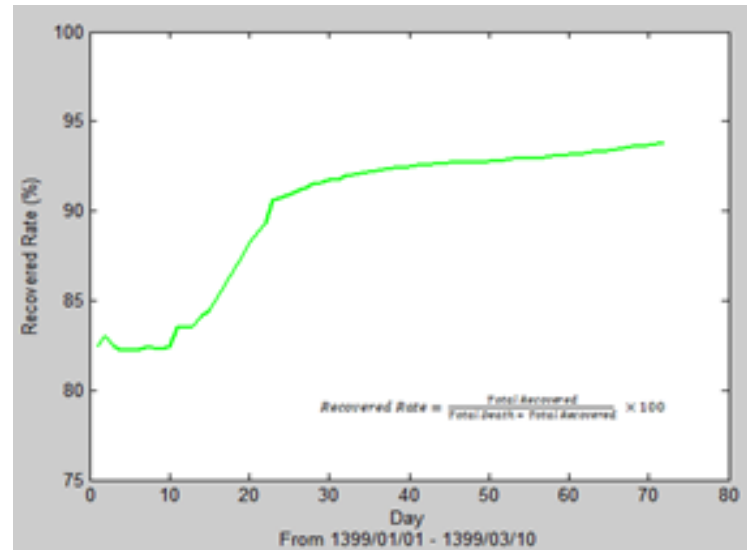

تا با كمك اين نرخ بتوان به تصويرى روشنتر از وضعيث فراكيرى و اثركذارى يك بيمارى دست يافت.

اييدميولوريستها براى محاسبه نرخ بهبود، شمار بهيبوديافتكان

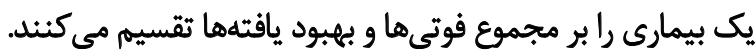

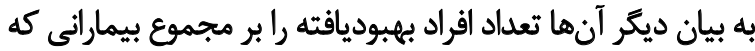
سرنوشتشان مشخص شده است، تقسيم مى كنند (فرمول شماره ب).

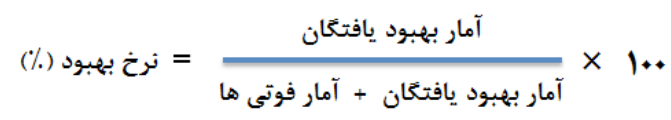

همجنين جهت محاسبه نرخ مركومير، تعداد افراد فوتشده به به

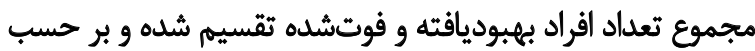

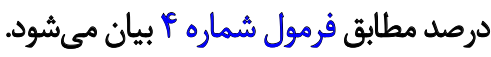

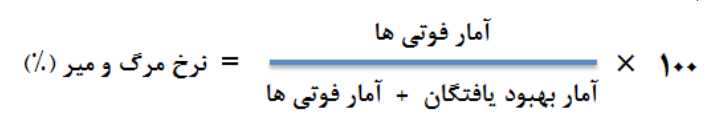

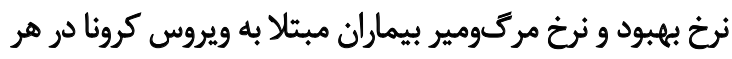

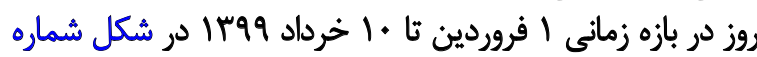

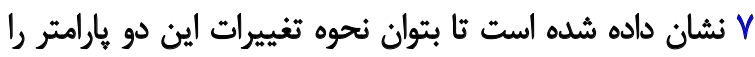
بروسى كرد.

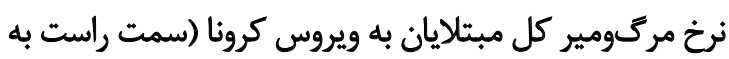

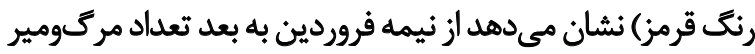

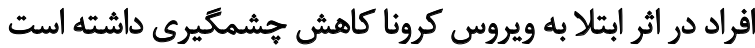
و اين ميزان از اوايل ارديبهشت به كمتر از ل لدرصد رسيده است أريت.

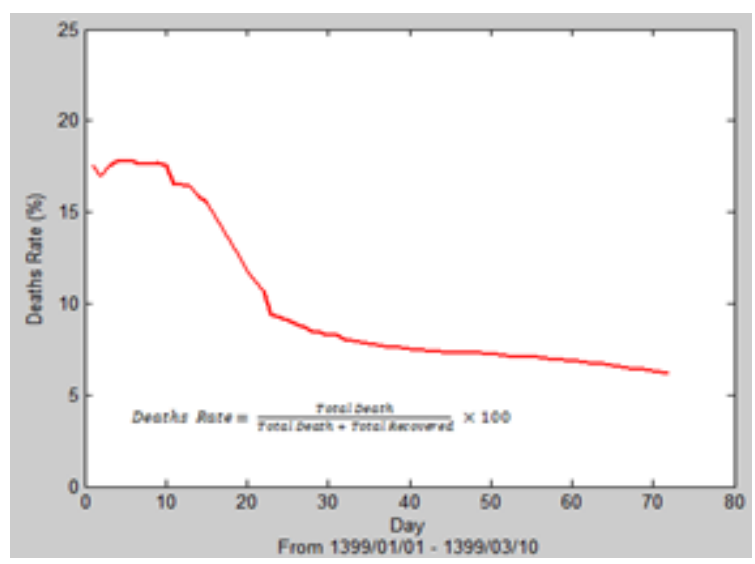

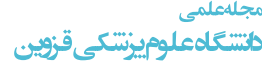

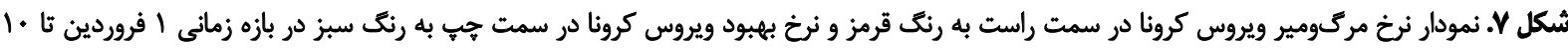




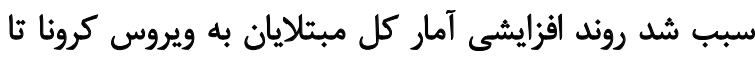

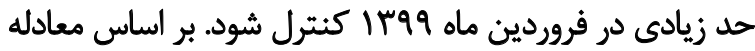

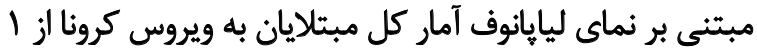

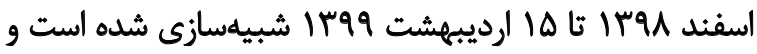

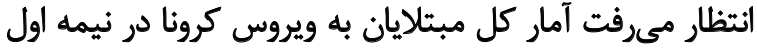

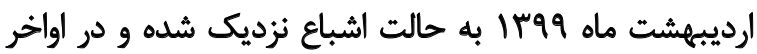

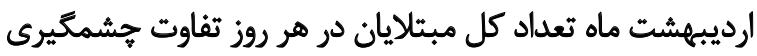

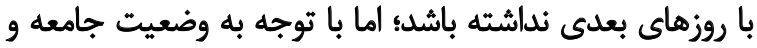

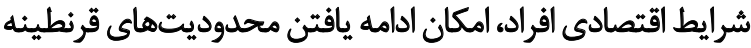

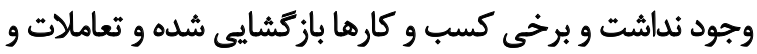

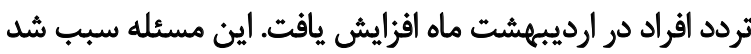

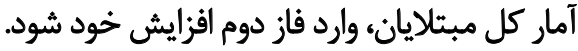

مقدار نماى ليايانوف محاسبهشده در فاز دوم اقزايش آمار كل

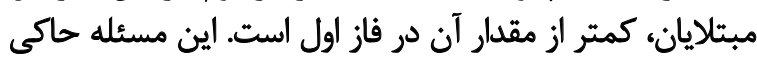

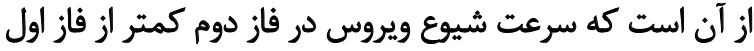

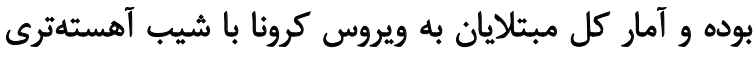

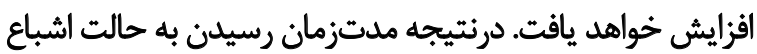

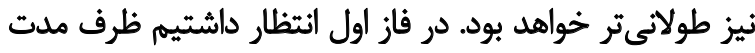

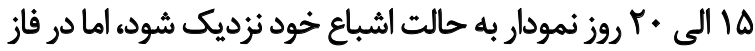

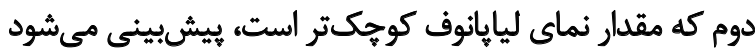

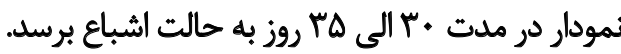

در خصوص آمار كل جانباختكان نيز نثايج به همين

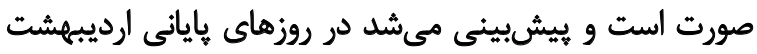

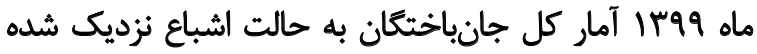

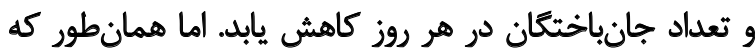

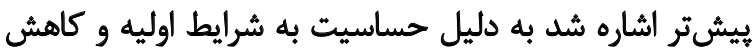

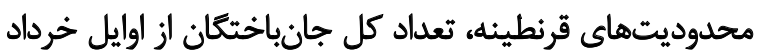

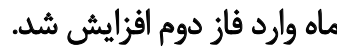

كنترل آمار كل مبتلايان و شناسايى داروهاى مؤثر بر كاهش

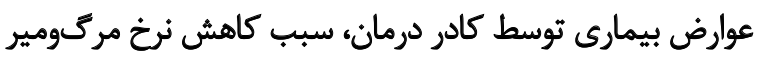

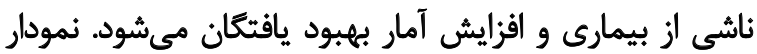

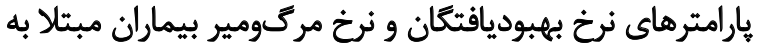

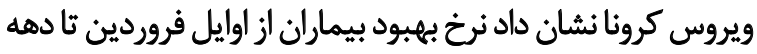

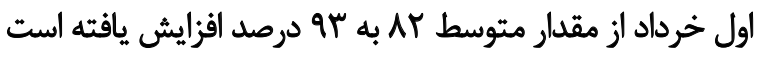

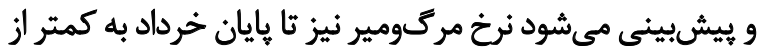

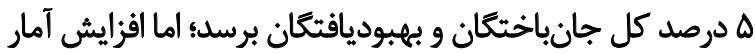

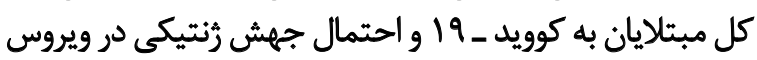

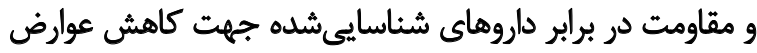

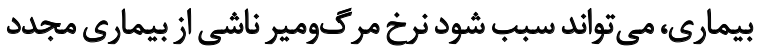
افزايش يافته و آمار بهبوديافتشان كاهش يبيدا كندي

به دليل آشوبكون بودن شيوع ويروس، تغيير بسيار اندك در

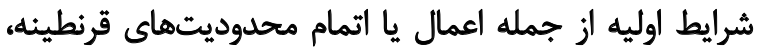

ليايانوف محاسبهشده و شيب منحنى در فاز دوم كمتر از فاز اول الست.

شبيهسازى تعداد كل جانباختكان در بازه زمانى اول (شكل

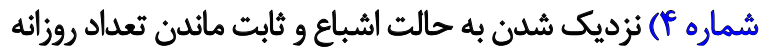

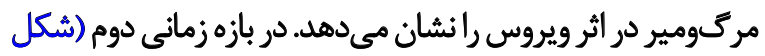

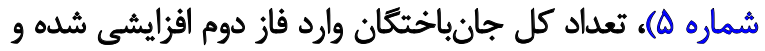

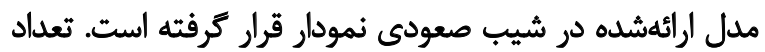

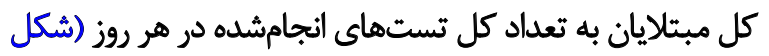

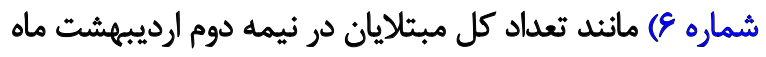

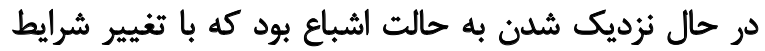

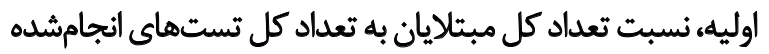

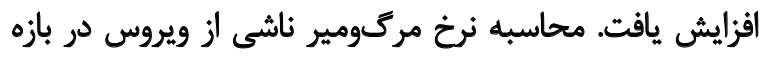

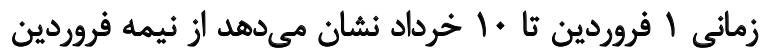

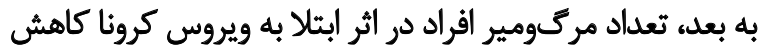

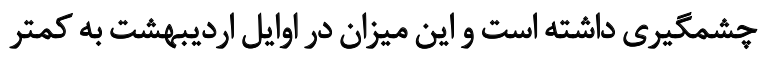

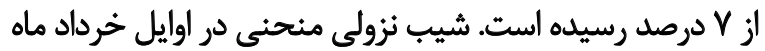

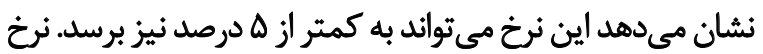

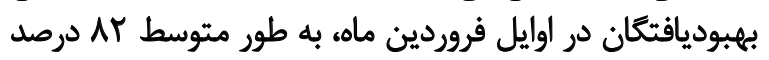

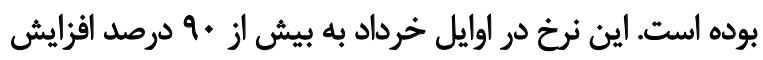
يافته است (شكل شماره Y).

\section{بحث و تتيجلكَّيرى}

كر مطالعه حاضر، شبيهسازى آمار كل مبتلايان بهان ويروس

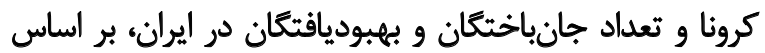

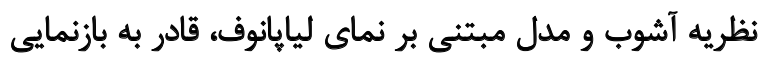

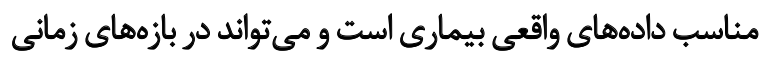

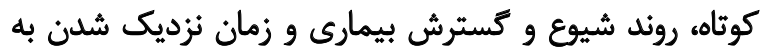
حالت اشباع را ييشبينى كند.

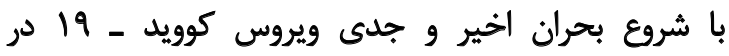

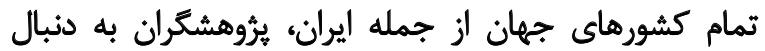

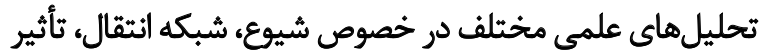

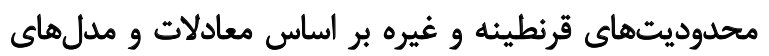

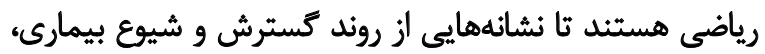

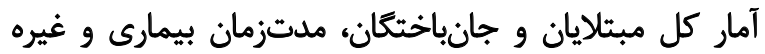

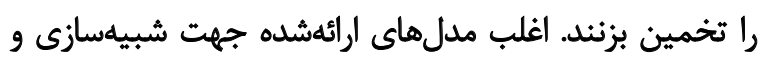

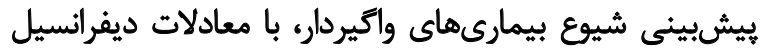

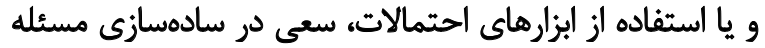

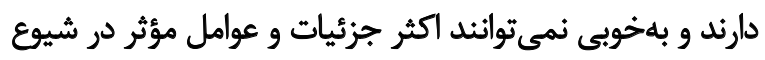

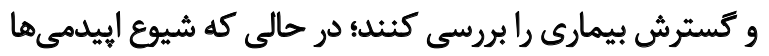

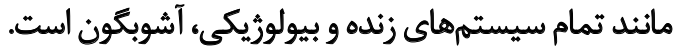

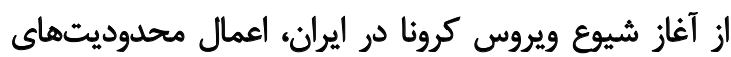

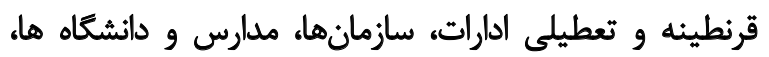


رعايت نكات بهداشتى توسط مردم، جهش رئتيكى ويروس،

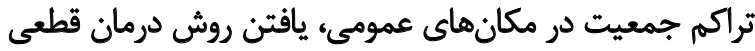

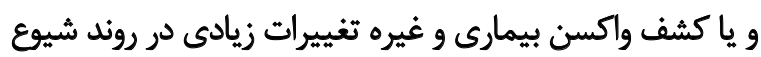

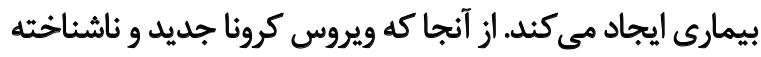

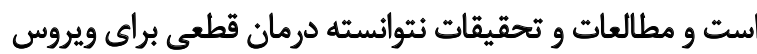

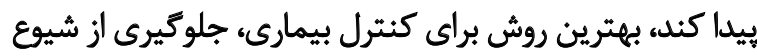

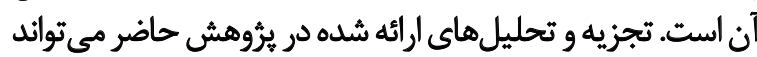

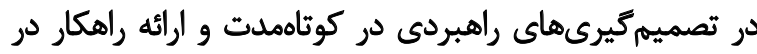

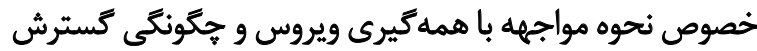

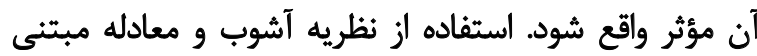

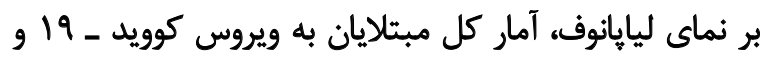

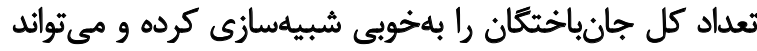
ييشينى مناسبى از شيوع بيمارى ارائه دهد.

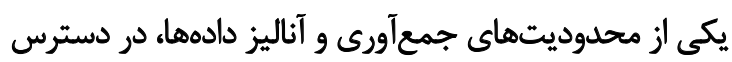

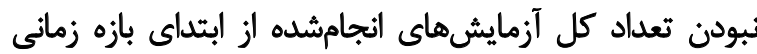

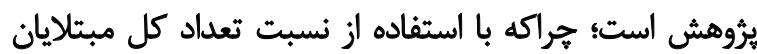

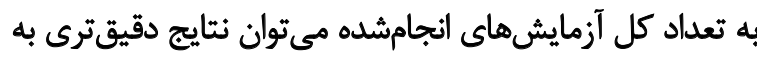

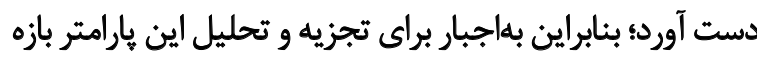

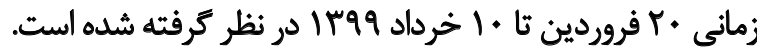

ملاحظاث اخالاقى

بيروى از أصول اخلاق يثوهشش اين مقاله از نوع فراتحليل است و نمونه انسانى و حيوانى نداشته

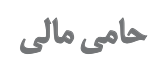

اين ثيروهش هيجگونه كمك مالى از سازمانىهاى دولتى، خصوصى و غيرانتفاعى دريافت نكرده است.

$$
\text { مشاركت ثويسندكان }
$$

مفهومسازى، روششناسى، نظارت و مديريت برورثه: سعيده

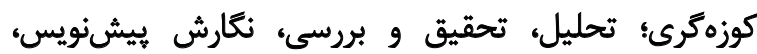

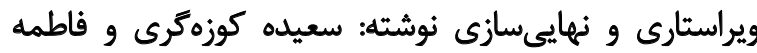
محمدى؛ اعتبارسنجى و منابع: فاطمه محمدى نئ.

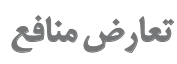

بنابر اظهار نويسندكان اين مقاله تعارض منافع ندارد. 


\section{References}

[1] Bauch CT. The role of mathematical models in explaining recurrent outbreaks of infectious childhood diseases. In: Brauer $F$, van den Driessche P, Wu J, editors. Mathematical Epidemiology. Berlin: Springer; 2008. p. 297-319. [DOI:10.1007/978-3540-78911-6_11]

[2] Pourbohloul B, Meyers LA, Skowronski DM, Krajden M, Patrick DM, Brunham RC. Modeling control strategies of respiratory pathogens. Emerg Infect Dis. 2005; 11(8):1249-56. [DOI:10.3201/eid1108.040449] [PMID] [PMCID]

[3] Ssematimba A, Hagenaars TJ, de Jong MCM. Modelling the wind-borne spread of highly pathogenic avian influenza virus between farms. PLoS One. 2012; 7(2):e31114. [DOI:10.1371/ journal.pone.0031114] [PMID] [PMCID]

[4] Briggs ADM, Wolstenholme J, Blakely T, Scarborough P. Choosing an epidemiological model structure for the economic evaluation of non-communicable disease public health interventions. Popul Health Metr. 2016; 14:17. [DOI:10.1186/ s12963-016-0085-1] [PMID] [PMCID]

[5] Garnerin P, Valleron AJ. The French communicable diseases computer network: A technical view. Comput Biol Med. 1992; 22(3):189-200. [DOI:10.1016/0010-4825(92)90015-F]

[6] Toubiana L, Vibert JF. A neural network model for the spread of communicable diseases. In: Gierl L, Cliff AD, Valleron AJ, Farrington $\mathrm{P}$, Bull $\mathrm{M}$, editors. Geomed' 97 . Wiesbaden: Springer Vieweg Verlag; 1998. p. 249-259. [DOI:10.1007/978-3-32295397-1_19]

[7] Perez L, Dragicevic S. An agent-based approach for modeling dynamics of contagious disease spread. Int J Health Geogr. 2009; 8:50. [DOI:10.1186/1476-072X-8-50] [PMID] [PMCID]

[8] Verity R, Okell LC, Dorigatti I, Winskill P, Whittaker C, Imai N, et al. Estimates of the severity of coronavirus disease 2019: A model-based analysis. Lancet Infect Dis. 2020; 20(6):669-77. [DOI:10.1016/S1473-3099(20)30243-7]

[9] Silverman JD, Hupert N, Washburne AD. Using influenza surveillance networks to estimate state-specific prevalence of SARS-CoV-2 in the United States. Sci TransI Med. 2020; 12(554):eabc1126. [DOI:10.1126/scitranslmed.abc1126] [PMID] [PMCID]

[10] Cao S, Feng P, Shi P. Study on the epidemic development of COVID-19 in Hubei province by a modified SEIR model. J Zhejiang Univ (Med Sci). 2020; 49(2):178-84. http://www.zjujournals.com/med/EN/10.3785/j.issn.1008-9292.2020.02.05

[11] Chen TM, Rui J, Wang QP, Zhao ZY, Cui JA, Yin L. A mathematical model for simulating the phase-based transmissibility of a novel coronavirus. Infect Dis Poverty. 2020; 9(1):24. [DOI:10.1186/s40249-020-00640-3] [PMID] [PMCID]

[12] Basiri MR. Theory about treatments and morbidity prevention of corona virus disease (covid-19). J Pharm Pharmacol. 2020; 8:89-90. [DOI:10.17265/2328-2150/2020.03.004]

[13] Alipour A, Ghadami A, Alipour Z, Abdollahzadeh H. Preliminary validation of the Corona Disease Anxiety Scale (CDAS) in the Iranian sample. J Health Psychol. 2020; 8(32):163-75. [In Persian] http://hpj.journals.pnu.ac.ir/article_6571_en.html
[14] Pourghaznein T, Salati S. National approach in response to the COVID-19 pandemic in Iran. Int J Community Based Nurs Midwifery. 2020; 8(3):275-6. [DOI:10.30476/IJCBNM.2020.85928.1308] [PMID] [PMCID]

[15] Pearsall J. The concise Oxford English dictionary. Oxford: Oxford University Press; 2002. https://books.google.com/ books?id=a4rIAAAAMAAJ\&dq

[16] Chaté H, Villermaux E, Chomaz JM. Mixing: Chaos and turbulence. Berlin: Springer Science \& Business Media; 2012. https://books.google.com/books?id=0awJCAAAQBAJ\&dq

[17] Redondo JM. Turbulence, entropy and dynamics [Internet]. 2014 [Updated 2014 December]. Available from: https:// upcommons.upc.edu/bitstream/handle/2117/86131/Turbulence_Entropy_and_Dynamics.pdf

[18] Hashemi Golpayegani SMR. Chaos and its applications in engineering. Tehran: Amirkabir University of Technology; 2009. [In Persian] http://opac.nlai.ir/opac-prod/bibliographic/1906260

[19] Kouzehgari S. Explanation of international system behavior based on chaos principal, case study the Middle East region [PhD. dissertation]. Tehran: Tarbiat Modares University; 2015. [In Persian] https://ganj.irandoc.ac.ir//\#/articles/4acf14d31a1 25de353490e2fc2c09d47

[20] Kinsner W. Characterizing chaos through Lyapunov metrics. IEEE Transactions on Systems, Man, and Cybernetics, Part C (Applications and Reviews). 2006; 36(2):141-51. [DOI:10.1109/ TSMCC.2006.871132]

[21] Nazarimehr F, Jafari S, Hashemi Golpayegani SMR, Sprott JC. Can Lyapunov exponent predict critical transitions in biological systems? Nonlinear Dyn. 2017; 88(2):1493-500. [DOI:10.1007/ s11071-016-3325-9]

[22] Schuster HG. Deterministic chaos. Hoboken: Wiley; 1995. https://books.google.com/books?id=mZzvAAAAMAAJ\&q

[23] Nychka D, Ellner S, Gallant AR, McCaffrey D. Finding chaos in noisy systems. J R Stat Soc B. 1992; 54(2):399-426. [DOI:10.1111/j.2517-6161.1992.tb01889.x]

[24] McCue LS, Troesch AW. Use of Lyapunov exponents to predict chaotic vessel motions. In: Almeida Santos Neves M, Belenky VL, de Kat JO, Spyrou K, Umeda N, editors. Contemporary Ideas on Ship Stability and Capsizing in Waves. Dordrecht: Springer; 2011. p. 415-432. [DOI:10.1007/978-94-007-1482-3_23]

[25] Moeini A, Abrishami H, Ahrari M. Using lyapunov exponent for modeling time series of oil price based on logistic map. Tahghighat- E- Eghtesadi. 2006; (76):77-100. [In Persian] https://www.sid.ir/fa/journal/ViewPaper.aspx?ID=58646

[26] Moeini Sedeh S, Arjmand N, Sanjari MA, Mokhtarinia HR, Asgari M, Parnianpour M. Nonlinear analysis of dynamic lumbar stability during repetitive trunk flexion extension at symmetric and asymmetric directions. Iran J Biomed Engr. 2013; 7(4):33340. [In Persian] http://www.ijbme.org/article_13281_en.html

[27] Ferriere R, Gatto M. Lyapunov exponents and the mathematics of invasion in oscillatory or chaotic populations. Theor Popul Biol. 1995; 48(2):126-71. [DOI:10.1006/tpbi.1995.1024] 
[28] Dehghanpisheh B. Coronavirus has spread to nearly all Iran provinces: President [Internet]. 2020 [Updated 2020 March 4]. Available from: https://www.reuters.com/article/us-healthcoronavirus-iran-rouhani-idUSKBN20R1ES

[29] Worldometer. COVID-19 coronavirus pandemic [Internet]. 2020. [Updated 2020 September 23]. Available from: https:// www.worldometers.info/coronavirus/

[30] Bonasera A, Zhang S. Chaos, percolation and the coronavirus spread. Front Phys. 2020; 8:171. [DOI:10.3389/ fphy.2020.00171] 
This Page Intentionally Left Blank 